\title{
Ponavljajuća ruptura jajnika - komplikacija medicinskog postupka ili upozorenje na povećane rizike za nepovoljan ishod u reprodukcijskoj dobi? Prikaz slučaja
}

\section{Recurrent ovarian rupture - a complication of a medical procedure or a warning of increased risk for an adverse outcome in reproductive age? Case report}

\author{
Ana Bošnjak ${ }^{1 *}$, Neda Smiljan Severinski ${ }^{2}$
}

\begin{abstract}
Sažetak. Cilj: Prikazati slučaj pacijentice s ponavljajućim rupturama jajnika s ciljem rasprave moguće etiologije rupture koja može nastati u različitim fazama liječenja u predisponiranih pacijentica. Prikaz slučaja: Pacijentica u dobi od 28 godina zaprimljena je u hitnu ginekološku ambulantu zbog jakih bolova u donjem dijelu abdomena praćenih dispnejom i općim lošim osjećanjem. Tog jutra pacijentica je bila na aspiraciji oocita. U krvnoj slici bile su snižene vrijednosti eritrocita, hemoglobina i hematokrita. Transvaginalnim ultrazvukom postavljena je sumnja na hematoperitoneum. Indicirana je hitna dijagnostička laparoskopija kojom je potvrđeno intraperitonealno krvarenje, a izvor je bio rupturirani jajnik. Hemostaza je učinjena tijekom zahvata termokauterizacijom. Nakon pet godina pacijentica je nastavila liječenje neplodnosti in vitro fertilizacijom u prirodnom ciklusu u kojem je učinjen prijenos zametka. Dva dana kasnije javlja se u hitnu ginekološku ambulantu zbog bolova u abdomenu. Ultrazvučnom dijagnostikom postavljena je sumnja na hematoperitoneum koji je potvrđen dijagnostičkom laparoskopijom, a krvarenje je zaustavljeno termokauterizacijom. Tri tjedna nakon prijenosa zametka transvaginalnim ultrazvukom potvrđen je intrauterino smješten gestacijski mjehurić, čime je potvrđena trudnoća. U 26. tjednu trudnoće započeo je prijevremeni porod prsnućem vodenjaka te je porod dovršen carskim rezom. Zaključak: Tijek liječenja neplodnosti i zbivanja tijekom perinatalnog razdoblja ukazuju da su ponavljane rupture jajnika moguće u predisponiranih pacijentica. Prikazani slučaj ukazuje na skupinu pacijentica koja je sklonija komplikacijama u različitim okolnostima reprodukcijske dobi.
\end{abstract}

Ključne riječi: hematoperitoneum; in vitro fertilizacija; ovarijska cista; prijevremeni porod

Abstract. Aim: To present a patient with recurrent ovarian ruptures in order to discuss the possibility of etiology of rupture that may occur at different stages of treatment in therefore predisposed patients. Case report: A-28-year-old patient was admitted to an emergency gynecological ambulance due to pain in the lower abdomen, dyspnea, and general weakness. That morning, the oocyte retrieval was done. In the laboratory findings, erythrocytes, hemoglobin, and hematocrit were reduced. Transvaginal ultrasound raised the suspicion of hemoperitoneum so urgent diagnostic laparoscopy was indicated. It confirmed the intraperitoneal bleeding whose cause was the ruptured ovary. Hemostasis was performed during the thermocauterization procedure. After five years, the patient continued infertility treatment by in vitro fertilization in the natural cycle in which the embryo was transferred. Two days later, the patient was admitted to an emergency gynecological ambulance due to pain in the lower abdomen. After the examination, the hemoperitoenum was suspected and confirmed by diagnostic laparoscopy, the bleeding was stopped. Three weeks after embryo's transfer, the transvaginal ultrasound confirmed gestatinal sac located in uterus which
${ }^{1}$ Sveučilište u Rijeci, Medicinski fakultet, Rijeka, Hrvatska

${ }^{2}$ Klinika za ginekologiju i porodništvo, Klinički bolnički centar Rijeka, Hrvatska

*Dopisni autor:

Ana Bošnjak

Sveučilište u Rijeci, Medicinski fakultet Braće Branchetta 20, 51000 Rijeka

E-mail: bosnjak.ana239@gmail.com

http://hrcak.srce.hr/medicina 
confirmed the pregnancy. In the $26^{\text {th }}$ week of pregnancy, preterm labor was caused by the rupture of the membranes so the delivery was completed by Caesarean section. Conclusion: The infertility treatment and events during the perinatal period indicate that recurrent ovarian ruptures are possible in predisposed patients. The presented case indicated a group of patients who are more prone to complications in different circumstances of reproductive age.

Key words: hemoperitoneum; in vitro fertilization; ovarian cyst; preterm labor

Hiperstimulacija jajnika navodi se kao najozbiljnija komplikacija liječenja s učestalošću od 3 do $6 \%$ kod pacijentica sa srednje teškim i teškim oblikom bolesti, a nastaje nakon upotrebe gonadotropina za stimulaciju jajnika. Opsežnija krvarenja uzrokovana rupturom jajnika opisuju se kao vrlo rijetke komplikacije liječenja neplodnosti s učestalošću od 0,03 do 0,5\% u svim IVF ciklusima, a povezana su s lijekovima za stimulaciju jajnika ili indukciju ovulacije.

\section{UVOD}

In vitro fertilizacija (engl. in vitro fertilization; IVF) najsloženija je metoda liječenja neplodnosti kojom se omogućava spajanje gameta i oplodnja izvan tijela. Embriji stvoreni na taj način prenose se u materište, nakon čega se očekuje začeće ${ }^{1}$. Hiperstimulacija jajnika navodi se kao najozbiljnija komplikacija liječenja s učestalošću od 3 do $6 \%$ kod pacijentica sa srednje teškim i teškim oblikom bolesti, a nastaje nakon upotrebe gonadotropina za stimulaciju jajnika². Opsežnija krvarenja uzrokovana rupturom jajnika opisuju se kao vrlo rijetke komplikacije liječenja neplodnosti s učestalošću od 0,03 do 0,5\% u svim IVF ciklusima, a povezana su s lijekovima za stimulaciju jajnika ili indukciju ovulacije. Češće nastaju u vrijeme ili nakon aspiracije jajnih stanica, a ponekad i nakon prijenosa zametka u stimuliranom ciklusu ${ }^{3,4}$. Liječenje u prirodnom ciklusu indicira se kako bi se prevenirale ponavljajuće rupture jajnika ${ }^{4}$. U slučaju naše pacijentice ruptura jajnika dogodila se i nakon prijenosa zametka u prirodnom ciklusu, što je vrlo neobično i zbog čega postaje nejasno jesu li ponavljajuće rupture jajnika komplikacija medicinskog postupka ili su zapravo uzrok povećanog rizika od komplikacija i nepovoljnog ishoda u reprodukcijskoj dobi. Liječenje abdominalnih krva- renja uključuje kirurški zahvat u općoj anesteziji radi postizanja hemostaze i vitalnog zbrinjavanja pacijentice, što je ozbiljna posljedica uobičajeno jednostavnog liječenja neplodnosti, koje se obavlja ambulantno ${ }^{5}$.

U ovome članku bit će prikazan slučaj pacijentice s ponavljajućom rupturom jajnika - prvi put nakon aspiracije jajnih stanica u stimuliranom IVF ciklusu, a zatim nakon dugog vremenskog razdoblja drugi put, nakon prijenosa zametka u prirodnom ciklusu. Nadalje, bit će raspravljena moguća etiologija rupture jajnika koja može nastati u različitim fazama liječenja u predisponiranih pacijentica. Radi se o zdravoj ženi, koja je u postupak liječenja in vitro fertilizacijom uključena zbog teške muške neplodnosti. Pacijentica je dala potpisanu suglasnost za publiciranje prikaza medicinskog slučaja.

\section{PRIKAZ SLUČAJA}

U hitnu ginekološku ambulantu u večernjim satima zaprimljena je pacijentica $u$ dobi od 28 godina zbog jakih bolova u donjem dijelu abdomena praćenih dispnejom i općim lošim osjećanjem. U jutarnjim satima pacijentica je bila na aspiraciji oocita, nakon minimalne stimulacije jajnika klomifen citratom tijekom 10 dana (Klomifen ${ }^{\circledR}$, Belupo, Hrvatska), a otpuštena je kući dobrog općeg stanja dva sata nakon zahvata. Kod prijama pacijentica je bila blijeda, žalila se na jake bolove u trbuhu, što ju je ometalo u spontanom kretanju. Izmjeren krvni tlak bio je blago snižen (100/60 $\mathrm{mmHg})$, a puls ubrzan (100/min). U krvnoj slici bile su značajnije snižene vrijednosti eritrocita ( $E$ $3,33 \times 1012 / L)$, hemoglobina (Hb $92 \mathrm{~g} / \mathrm{L}$ ), hematokrita (Hct 0,286 L/L). Transvaginalnim ultrazvukom (Aloca prosound $\alpha 6$, Aloca co.) utvrđena je retrouterina hematokela $(7 \times 4 \mathrm{~cm})$, a ispod obaju rebrenih lukova prikazani su stupci slobodne tekućine. S obzirom na anamnestičke podatke, laboratorijske abnormalnosti i patološki nalaz transvaginalnog ultrazvuka postavljena je sumnja na hematoperitoneum. Indicirana je hitna dijagnostička laparoskopija kojom je potvrđeno obilno intraperitonealno krvarenje prisutno i pod ošitom (1,5 L tekuće i ugrušane krvi). Izvor krvarenja bio je višestruko rupturirani desni jajnik, s nastalom velikom hematokelom, koja je ispunjavala ci- 
jeli Douglasov prostor. Krvarenje je zaustavljeno termokauterizacijom, aspirirana je tekuća i ugrušana krv, a peritonelna šupljina obilno isprana otopinom visokomolekularnog dekstrana (Voluvent $^{\oplus}$, Fresenius Kabi). Pacijentica je otpušena iz bolnice idućeg dana dobrog općeg stanja, uz preporuku mirovanja i kontrole u ginekološkoj ambulanti po dogovoru.

Nakon pet godina od prvog incidenta pacijentica se ponovno javila radi nastavka liječenja ranije dijagnosticirane neplodnosti uzrokovane muškim čimbenikom. Prethodno su učinjene hematološke pretrage, testovi zgrušavanja krvi i genetička molekularna analiza čimbenika koagulacije, koji su bili normalni. Odabran je postupak in vitro fertilizacije u prirodnom ciklusu kako bi se izbjegla stimulacija jajnika i najviše moguće smanjio rizik ponavljanja rupture jajnika. Nakon aspiracije jajne stanice pacijentica je dobrog općeg stanja otpuštena kući, a tri dana zatim učinjen je i prijenos jednog 8-staničnog zametka. Dva dana nakon prijenosa zametka pacijentica je primljena u hitnu ginekološku ambulantu zbog jakih bolova u donjem desnom kvadrantu abdomena koji su se širili u desno lumbalno područje. Abdomen je bio mekan i bolan na dublju palpaciju suprapubično, uz pozitivnu lumbalnu sukusiju desno. Transvaginalnim ultrazvukom prikazan je uvećani desni jajnik sa žutim tijelom i sumnjom na manji ugrušak. U Douglasovom prostoru prikazan je stupac slobodne tekućine dužine $50 \mathrm{~mm}$. Na osnovi anamnestičkih podataka, kliničke slike i nalaza transvaginalnog ultrazvuka postavljena je sumnja na hematoperitoneum. Indicirana je dijagnostička laparoskopija kojom je potvrđeno krvarenje u peritonealnu šupljinu, a mjesto krvarenja bilo je nekrotično rupturirano žuto tijelo desnog jajnika. Hemostaza je učinjena termokauterizacijom i parcijalnom resekcijom desnog jajnika. Uslijedilo je obilno ispiranje peritonealne šupljine fiziološkom otopinom. Pacijentica je idući dan otpuštena kući dobrog općeg stanja, uz preporuku mirovanja i kontrole radi vađenja šavova.

Tri tjedna nakon prijenosa zametka pacijentica se javila na pregled $s$ nalazom serumskog beta hCG koji je iznosio 6360 IU/L. Transvaginalnim ultrazvukom potvrđen je intrauterino smješten gestacijski mjehurić $\mathrm{s}$ jednim plodom i pozitivnom srčanom akcijom. Biometrija je odgovarala sed- mom tjednu gestacije, čime je potvrđena uredna trudnoća. U 26. tjednu trudnoće prilikom redovne kontrole, trudnica je nakon ultrazvučnog probira hospitalizirana zbog prijetećeg prijevremenog poroda i liječena je tokoliticima. Unatoč primjeni terapije za tokolizu, dolazi do prijevremenog prsnuća vodenjaka, a zbog prezentacije ploda zatkom, porod je dovršen carskim rezom. Porođeno je vitalno žensko novorođenče, koje je idućih mjeseci zadržano na Odjelu neonatološkog intenzivnog liječenja. Pacijentica je otpuštena kući dobrog općeg stanja sedmog dana nakon carskog reza.

\section{RASPRAVA}

Prikazali smo slučaj početno zdrave, reprodukcijski mlade žene koja je u program liječenja postupkom in vitro fertilizacije ušla zbog partnera s teškom muškom neplodnošću i kod koje nije početno bilo rizičnih čimbenika za liječenje ili trudnoću. Suprotno očekivanom, tijekom liječenja neplodnosti došlo je do opetovanih abdominalnih krvarenja koja su za pacijenticu bila životno ugrožavajuća. Posebnost slučaja je i kirurški zahvat koji je uključivao resekciju žutog tijela koje je «čuvar rane trudnoće». Usprkos tomu, zanesena je vitalna intrauterina trudnoća. Točan razlog ponavljanih abdominalnih krvarenja nije utvrđen, iako je početni zaključak bio vezan za komplikaciju medicinske intervencije.

Najčešća komplikacija aspiracije jajnih stanica jest vaginalno krvarenje $s$ učestalošću od 1,4 do 18,4 \%. Nastaje zbog oštećenja krvnih žila jajnika tijekom same punkcije i uglavnom prestaje samostalno ili primjenom kratkotrajne kompresije ${ }^{6}$. Nešto rjeđa, ali ozbiljnija komplikacija aspiracije jajnih stanica jest intraabdominalno krvarenje. Mogući uzorci razvoja takvog ishoda jesu manjak faktora koagulacije IX, nekrotizirajući vaskulitisi krvnih žila jajnika i antikoagulantna terapija ${ }^{7}$. U literaturi je opisana serija slučajeva u kojima se intraabdominalno krvarenje dogodilo u vremenskom periodu od 12 sati nakon aspiracije jajnih stanica u stimuliranom ciklusu. Zabilježen je i slučaj intraabdominalnog krvarenja koje se dogodilo dva sata nakon embriotransfera u prirodnom ciklusu koji nije završio trudnoćom ${ }^{4}$. Navedeni slučajevi, kao i prikaz naše pacijentice, ukazuju na mogućnost intraabdominalnog krvarenja kao jed- 
ne od ozbiljnih komplikacija postupka in vitro fertilizacije. Općenito, prirodni je ciklus poštedni oblik liječenja i indiciran je kod žena sa slabijim odgovorom jajnika, mlađih žena s dobrom prognozom ili prethodno neuspjelom stimulacijom ${ }^{8}$, a u naše je pacijentice bio indiciran zbog prevencije eventualne ponovne komplikacije aspiracije jajne stanice, što je ovim pristupom i ostvareno. Nažalost, krvarenje se u prirodnom ciklusu manifestiralo nakon prijenosa zametka, što nismo uspjeli uzročno objasniti jer su testovima koagulacije is-

lako je pravi uzrok višestrukih komplikacija u prikazane pacijentice ostao nepoznat, tijek liječenja neplodnosti i zbivanja tijekom perinatalnog razdoblja ukazuju da ponavljane rupture jajnika postoje u predisponiranih pacijentica.

ključene nepravilnosti krvarenja kao uzrok ponavljajućih ruptura jajnika i abdominalnog krvarenja. Daljnja reprodukcijska zbivanja u prikazanom slučaju vezana su uz komplikaciju prijevremenog poroda, koji je započeo promjenama i skraćivanjem cerviksa te prijevremenim prsnućem plodovih ovoja u drugom tromjesečju trudnoće. U traženju uzroka svih prikazanih komplikacija moguće je razmišljati o metaboličkim ili urođenim poremećajima vezivnoga tkiva, kao poveznici svih komplikacija u naše pacijentice, koje nismo dalje dijagnosticirali zbog objektivnih ograničenja. Nadalje, ponovljeni kirurški zahvat, s resekcijom jajnika i žutog tijela, poveznica je prema prijevremenom porodu jer se placenta u normalnoj trudnoći formira na osnovi funkcionalnog žutog tijela. Žuto je tijelo moćan izvor steroida u normalnoj početnoj trudnoći, što nije bio slučaj u naše pacijentice. I konačno, tijek trudnoća koje su začete metodama pomognute oplodnje općenito je rizičniji i opterećen mnogim komplikacijama u odnosu na trudnoće začete spontanim putem. Češća su rođenja djece s malom tjelesnom masom i prijevremeni porodi, što je bilo završno i u našem slučaju?

Liječenje neplodnosti metodama pomognute oplodnje nosi mnoge rizike i za ženu i za fetus ${ }^{9}$. Akutne kirurške komplikacije u liječenju relativno se brzo i dobro zbrinjavaju, bez većih trajnih posljedica za zdravlje pacijentica. lako je pravi uzrok višestrukih komplikacija u prikazane pacijentice ostao nepoznat, tijek liječenja neplodnosti i zbivanja tijekom perinatalnog razdoblja ukazuju da ponavljane rupture jajnika postoje u predisponiranih pacijentica.

\section{ZAKLJUČAK}

Početno utvrđen uzrok neplodnosti nije nužno povezan s komplikacijama liječenja koje se mogu češće očekivati kod parova. Prikazani slučaj pokazuje da bi mogla postojati određena skupina pacijentica koja je sklonija rupturama jajnika u različitim fazama liječenja neplodnosti, te da je s nastupom trudnoće također veći rizik komplikacija kroz perinatalno razdoblje.

Izjava o sukobu interesa: Autori izjavljuju kako ne postoji sukob interesa.

\section{LITERATURA}

1. Šimunić V. Kliničke smjernice za medicinski pomognutu oplodnju. Hrčak - Portal hrvatskih znanstvenih i stručnih časopisa. Medix 2013;19:132-146.

2. Kumar P, Sait Sameer F, Sharma A, Kumar M. Ovarian hyperstimulation syndrome. J Hum Reprod Sc 2011;4:70-75.

3. Sarhan A, Mausher S. Surgical complications of in vitro fertilization. Middle East Fertil Soc J 2007;12:1-7.

4. Aragona C, Mohamed M, Espinola MS, Linari A, Pecorini $F$, Micara $G$ et al. Clinical complications after transvaginal oocyte retrieval in 7,098 IVF cycles. Fertil Steril [Internet]. 2011;95. [cited 2020 May 30]. Available from: https://doi.org/10.1016/j.fertnstert.2010.07.1054.

5. Nouri C, Walch K, Promberg R, Kurz C, Tempfer C, Ott J. Severe haematoperitoneum caused by ovarian bleeding after transvaginal oocyte retrieval: A rectrospective analysis and systematic literature review. Reproductive BioMedicine Online [Internet]. 2014;29. [cited 2020 May 29]. Available from: https://doi.org/10.1016/j. rbmo.2014.08.008.

6. El-Shawarby S, Maraga R, Trew G, Lavery S. A review of complications following transvaginal oocyte retrieval for in vitro fertilization. Hum Fertil [Internet]. 2004;7. [cited 2020 May 29]. Available from: https://doi.org/10.1080/ 14647270410001699081.

7. Levi-Setti PE, Cirillo F, Scolaro V, Morenghi E, Heilbron F, Girardello D et al. Appraisal of clinical complications after 23,827 oocyte retrievals in a large assisted reproductive technology program. Fertil Steril [Internet]. 2018;109. [cited 2020 May 29]. Available from: https:// doi.org/10.1016/j.fertnstert.2018.02.002.

8. Wolff M. The role of Natural Cycle IVF in assisted reproduction. Best Pract Res Cllin Endocrinol Metab 2019;33:35-45.

9. Declercq E, Luke B, Belanoff C, Cabral H, Diop H, Gopal D et al. Perinatal outcomes associated with assisted reproductive technology: the Massachusetts outcomes study of assited reproductive technology (MOSART). Fertil Steril [Internet]. 2015;103. [cited 202030 May]. Available from: https://doi.org/10.1016/j.fertnstert.2014.12.119. 